\title{
Student Experiences with Engagement in a Nursing and Physical Therapy Interprofessional Education Simulation
}

\author{
Sarah Koplow \\ Nova Southeastern University, sarahkoplow@gmail.com \\ Melissa Morris \\ Nova Southeastern University, mm2409@nova.com \\ Shari Rone-Adams \\ Nova Southeastern University, srone@nova.edu \\ Heather Hettrick \\ Nova Southeastern University, hh124@nova.edu \\ Bini Litwin \\ Nova Southeastern University, blitwin@nova.edu
}

See next page for additional authors

Follow this and additional works at: https://nsuworks.nova.edu/ijahsp

Part of the Critical Care Nursing Commons, Educational Assessment, Evaluation, and Research Commons, Interprofessional Education Commons, Other Medicine and Health Sciences Commons, Other Nursing Commons, and the Physical Therapy Commons

\section{Recommended Citation}

Koplow S, Morris M, Rone-Adams S, Hettrick H, Litwin B, Soontupe LB, et al. Student Experiences with Engagement in a Nursing and Physical Therapy Interprofessional Education Simulation. The Internet Journal of Allied Health Sciences and Practice. 2020 Jan 01;18(1), Article 3.

This Manuscript is brought to you for free and open access by the College of Health Care Sciences at NSUWorks. It has been accepted for inclusion in Internet Journal of Allied Health Sciences and Practice by an authorized editor of NSUWorks. For more information, please contact nsuworks@nova.edu. 


\title{
Student Experiences with Engagement in a Nursing and Physical Therapy Interprofessional Education Simulation
}

\begin{abstract}
Purpose: Interprofessional Education (IPE) incorporated into healthcare discipline instruction has been shown to be successful in improving the understanding perceptions of complimentary professions. The purpose of this mixed method study was to measure differences in perceptions of early Baccalaureate of Science in Nursing (BSN) students and Doctor of Physical Therapy (DPT) with participation in a immersive interprofessional education experience. Method: Students completed a pre and posttest survey consisting of the Readiness for Interprofessional Learning Scale and several short answer qualitative questions. Cohorts of BSN and DPT students participated in a computerized mannequin simulation experience or a hybrid simulation. Results: Students indicated they learned about each other's scope of practice and recognized the benefits of teamwork through collaboration. Conclusion: Students showed increased knowledge of the other profession, appreciated the opportunity for interprofessional learning, and were interested in having more IPE simulation learning experiences.
\end{abstract}

\section{Author Bio(s)}

Sarah M. Koplow, PhD, APRN, AGPCNP-BC, is an assistant professor in the Ron and Kathy Assaf College of Nursing at Nova Southeastern University in Ft. Lauderdale, FI.

Melissa Morris, MSN, RN, CPN, CHSE is the Director of Simulation and Innteractive Technology at the Dr. Pallavi Patel College of Health Care Sciences at Nova Southeastern University in Ft. Lauderdale, Fl.

Shari Rone-Adams, PT, MHSA, DBA is the Chair of the Physical Therapy Department, and an associate professor at the Dr. Pallavi Patel College of Health Care Sciences at Nova Southeastern University in Ft. Lauderdale, $\mathrm{Fl}$.

Heather Hettrick PT, PhD, CWS, CLT-LANA, CLWT is an associate professor in the physical therapy department at the Dr. Pallavi Patel College of Health Care Sciences at Nova Southeastern University in Ft. Lauderdale, $\mathrm{Fl}$.

Bini Litwin, PT, DPT, PhD, MBA is the chair of the TDPT program in the Physical Therapy Department and an associate professor at the Dr. Pallavi Patel College of Health Care Sciences at Nova Southeastern University in Ft. Lauderdale, Fl.

Lisa B. Soontupe, EdD, RN, CNE is an associate professor in the Ron and Kathy Assaf College of Nursing at Nova Southeastern University in Ft. Lauderdale, Fl.

Archana Vatwani, PT, DPT, MBA, CLWT, CDP is an assistant professor in the Physical Therapy Department at the Dr. Pallavi Patel College of Health Care Sciences at Nova Southeastern University in Ft. Lauderdale, Fl.

\section{Acknowledgements}

We wish to acknowledge the support of Jo Ann Kleier, PhD, EdD, ARNP, ACNP-BC in her assistance with the statistical analysis. Permission form Dr. Kleier obtained.

\section{Authors}

Sarah Koplow, Melissa Morris, Shari Rone-Adams, Heather Hettrick, Bini Litwin, Lisa B. Soontupe, and Archana Vatwani 


\title{
The Internet Journal of Allied Health Sciences and Practice \\ Dedicated to allied health professional practice and education
}

Vol. 18 No. 1 ISSN 1540-580X

\section{Student Experiences with Engagement in a Nursing and Physical Therapy Interprofessional Education Simulation}

\author{
Sarah Koplow \\ Melissa Morris \\ Shari Rone-Adams \\ Heather Hettrick \\ Bini Litwin \\ Lisa B. Soontupe \\ Archana Vatwani \\ Nova Southeastern University \\ United States
}

\begin{abstract}
Purpose: Interprofessional Education (IPE) incorporated into healthcare discipline instruction has been shown to be successful in improving the understanding perceptions of complimentary professions. The purpose of this mixed method study was to measure differences in perceptions of early Baccalaureate of Science in Nursing (BSN) students and Doctor of Physical Therapy (DPT) with participation in a immersive interprofessional education experience. Method: Students completed a pre and posttest survey consisting of the Readiness for Interprofessional Learning Scale and several short answer qualitative questions. Cohorts of BSN and DPT students participated in a computerized mannequin simulation experience or a hybrid simulation. Results: Students indicated they learned about each other's scope of practice and recognized the benefits of teamwork through collaboration. Conclusion: Students showed increased knowledge of the other profession, appreciated the opportunity for interprofessional learning, and were interested in having more IPE simulation learning experiences.
\end{abstract}

Keywords: nursing, physical therapy, interprofessional education 


\section{INTRODUCTION}

In order for interprofessional teams to be effective, the old paridigms and beliefs of each discipline must be explored and challenged. ${ }^{1,2}$ When adults learn, their previously held beliefs can influence new experiences. ${ }^{2}$ Transformational learning guides learners to challenge assumptions and modify perceptions in forming new perspectives for team members. These new perspectives serve to facilitate the team in integrating their varying expertise and realm of decision-making abilities to communicate and collaborate for the best patient outcomes. ${ }^{1,2}$ Interprofessional education experiences incorporated within pre-licensure programs allow for individual disciplines to bring their unique knowledge base to a given situation. These experiences allows each profession to appreciate the other's perspective in collaborating to provide optimal population health outcomes. ${ }^{1,2}$

As part of the growing trend to enhance health professions education, the Institute of Medicine (IOM), a United States based, private, non-governmental institution created to improve the nation's health, declared working in interdisciplinary teams as one of its five core competencies that all clinicians should have, regardless of discipline. ${ }^{1}$ According to both the World Health Organization (WHO) and IOM, interdisciplinary practice provides patients the best care and access to health services through team members' collaboration on a treatment plan. Positive patient outcomes are best accomplished by sharing team members' expertise through cooperative coordination of patient care interventions, rather than working in a silo. ${ }^{1,3}$

The IOM report emphasized that promoting interprofessional collaboration requires interdisciplinary education. Additionally, the American Association of Colleges of Nursing (AACN) has emphasized the importance of working in interprofessional teams to provide patient-centered care that includes interprofessional communication and collaboration as part of the Essentials of Baccalaureate Education for Professional Nursing Practice. ${ }^{4}$ Correspondingly, the Commission of Accreditation in Physical Therapy Education (CAPTE) states in their accreditation standards that interprofessional education competencies be integrated into physical therapy educational programs to promote team based collaborative care. ${ }^{5}$ The Interprofessional Education Collaborative (IPEC), which is an alliance of health profession education programs that supports and advances interprofessional learning experiences, has identified four core competencies to facilitate teams and teamwork in promoting population health. IPEC recommends these competencies are integrated into the curriculum of health care programs to achieve client goals and promote interprofessional practice. ${ }^{6}$

Interprofessional Education (IPE) has been successful in improving attitudes, understanding, and perceptions of various healthcare discipline pre-licensure students. 7,8 Some studies found conflicting results, noting students reported positive experiences, but felt they lacked real-world experiences to work collaboratively. $8,9,10$ However, best practice models suggest incorporating IPE early in health profession education supports students in learning about not only their own, but also other health professions' roles. ${ }^{9}$ In the current literature, students felt interactions with other healthcare professionals should occur more on an individual basis (as opposed to a team), and did not feel positive about team-based learning. . $10,11,12^{2}$

Researchers suggest that if IPE were incorporated earlier in healthcare discipline education, students would view the experience in a more positive light.8,11,12 The National League of Nursing (NLN) and the Society for Simulation in Healthcare (SSH) have also advocated for interprofessional patient-based simulation education experiences to be initiated early in the curriculum of healthcare disciplines. Simulation helps develop skills and competencies needed for interprofessional practice. ${ }^{13}$ These simulation experiences allow students to be introduced to future partners in patient care, develop an understanding of their own role and responsibilities, and acquire insight into the role of other healthcare professionals. ${ }^{11}$

This current study explores an IPE simulation activity, early in the learner's curriculum, which incorporates Transformational Learning Theory. This theory claims learners bring with them previously held beliefs and experiences. ${ }^{2}$ The Transformational Learning Theory is an adult learning theory that has been utilized in health care simulation for critical self-reflection. ${ }^{14}$ When transformational learning occurs, there is a shift in the interpretation of those experiences, which ultimately leads to change in meanings, beliefs, and knowledge. Transformational learning forces the learner to become aware of how they approach their knowledge base and values. Thus, when change does occur, the student becomes more expansive and open in their perspectives. It has been suggested, early IPE exposure supports meaningful understanding of one's own role and how it is connected to other health professionals practice. 2,7

The purpose of this study was to measure differences in perceptions between early pre-licensure Baccalaureate of Science in Nursing (BSN) students and pre-licensure Doctor of Physical Therapy (DPT) students prior to and after participation in an immersive IPE experience. The research questions were:

1. Is there a change in perception of roles as they relate to the providing of health care after an immersive interprofessional simulation? 
2. Is there a change in perception regarding interprofessional learning experiences after an immersive interprofessional simulation?

\section{METHODS}

This was a mixed methods study involving the use of pre and post survey questionnaires administered to DPT and BSN students. The quantitative component utilized a quasi-experimental, cross sectional pre and post-test design. The qualitative data included the use of a short answer open ended questionnaire to provide a deeper understanding of the students' perceptions about IPE and the student's fellow discipline. The pre-test was administered by faculty from both disciplines just prior to the orientation and briefing on the day of the simulation. The post-test was administered by faculty from both disciplines at the conclusion of the debriefing of the IPE activity.

\section{Sample}

The study was conducted at a mid-sized private, not for profit University with undergraduate BSN and graduate DPT programs in the Southeastern United States. A convenience sample of BSN students enrolled in their first medical surgical course and DPT students enrolled in either their first or second medical systems course were included as participants. These groups of students were chosen as participants because there was alignment between the course objectives and content in the respective programs. Institutional Review Board approval (with exempt status) was obtained. Data was maintained in a locked cabinet in the office of one of the faculty members. The secured data had no participant identifying information. The pre and post-test questionnaires were coded with a number and an A or B to identify if they were pre or post activity.

Over a two-year period, three interprofessional simulation activities took place. Two simulation experiences utilizing computerized mannequins were performed. Participants included first year BSN students enrolled in their first adult health medical surgical nursing course and $2^{\text {nd }}$ year DPT students enrolled in their first medical systems course. The BSN student's course focused on chronic conditions with an emphasis on nursing management in the hospitalized setting. The DPT course focused on the complex medical patient in acute settings. The third simulation encounter was a hybrid simulation, which utilized student role-play with a body part task trainer. The students participating in this simulation were comprised of a different cohort of BSN students in their first adult health nursing course and a different cohort of first year DPT students enrolled in the systems management course as well as in an integumentary course. Faculty from the nursing and PT programs collaborated to adapt and implement an existing pre-scripted simulation patient encounter for all IPE simulations. The scenarios chosen were aligned with the BSN and DPT course objectives and the academic level of the student learners. Additionally, these scenarios provided opportunities for both nursing and physical therapy professions to utilize their acquired skill sets in providing interventions to achieve positive patient outcomes.

\section{Instrument}

Assessment of students' perceptions toward interprofessional education requires valid and reliable tools to ensure rigor. Although previous researchers have reported on the effectiveness of interprofessional education in pre-licensure programs, the lack of rigor of the standardized assessment tools used in these studies makes outcomes difficult to evaluate. ${ }^{15}$ This study utilized the revised version of the Readiness for Interprofessional Learning Scale (RIPLS), a tool that examines healthcare student's attitudes and beliefs of interprofessional teams. Although previous studies have established the validity and reliability of this tool, as part of the outcome analysis, this study assessed the reliability of the instrument used with this population. 16,17,18 The RIPLS is a 19-item 5point Likert questionnaire consisting of four subscales, Teamwork \& Collaboration, Negative Professional Identity, Positive Professional Identity, and Roles and Responsibilities.

In this study, students completed a paper RIPLS tool where they selected responses from 1-5, corresponding with strongly agree to strongly disagree. The responses were imported into the SPSS statistics software by the researchers. In addition to data collected from the RIPLS, the faculty also developed short answer qualitative questions that asked about previous participation in IPE, knowledge of the other discipline, perceived benefits of IPE, and future interest in further IPE experiences (available upon request). The questions were vetted by BSN and DPT faculty.

Table 1. Readiness for Interprofessional Learning Scale (RIPLS) Questionnaire:

\begin{tabular}{|l|l|}
\hline 1 & Learning with other students will help me become a more effective member of a health care team \\
\hline 2 & Patients would ultimately benefit if health-care students worked together to solve patient problems \\
\hline 3 & Shared learning with other health-care students will increase my ability to understand clinical problems \\
\hline 4 & $\begin{array}{l}\text { Learning with health-care students before graduation and licensure examination would improve relationships after } \\
\text { graduation and licensure examination }\end{array}$ \\
\hline 5 & Communications skills should be learned with other health-care students \\
\hline 6 & Shared learning will help me to think positively about other professionals \\
\hline
\end{tabular}




\begin{tabular}{|l|l|}
\hline 7 & For small group learning to work, students need to trust and respect each other \\
\hline 8 & Team-working skills are essential for all health-care students to learn \\
\hline 9 & Shared learning will help me to understand my own limitations \\
\hline 10 & I don't want to waste my time learning with other health-care students \\
\hline 11 & It is not necessary for health-care students to learn together \\
\hline 12 & Clinical problem-solving can only be learned with students from my own discipline \\
\hline 13 & $\begin{array}{l}\text { Shared learning with other health-care students will help me communicate better with patients and other } \\
\text { professionals }\end{array}$ \\
\hline 14 & I would welcome the opportunity to work on small group projects with other health-care students \\
\hline 15 & Shared learning will help to clarify the nature of patient problems \\
\hline 16 & Shared learning before graduation and licensure examination will help me become a better team worker \\
\hline 17 & The function for Registered Nurses and Physical Therapists is mainly to provide support for physicians \\
\hline 18 & I'm not sure what my professional role is/will be \\
\hline 19 & I have to acquire much more knowledge and skills than other health-care students \\
\hline
\end{tabular}

Table 2. Pre and post qualitative questions

\begin{tabular}{|c|c|}
\hline Pre & Post \\
\hline $\begin{array}{l}\text { Have you had previous experience with Interprofessional } \\
\text { Learning? }\end{array}$ & $\begin{array}{l}\text { If you are a nursing student, list three things you learned } \\
\text { today that you did not know about the profession of physical } \\
\text { therapy. }\end{array}$ \\
\hline If yes, what discipline (s) were included? & $\begin{array}{l}\text { If you are a physical therapy student, list three things you } \\
\text { learned today that you did not know about the profession of } \\
\text { nursing. }\end{array}$ \\
\hline $\begin{array}{l}\text { If you answered yes to the previous question list } 3 \text { benefits of } \\
\text { that interprofessional learning experience. }\end{array}$ & $\begin{array}{l}\text { Why is it important for nurses and physical therapist to } \\
\text { collaborate during patient care? }\end{array}$ \\
\hline $\begin{array}{l}\text { If you are a nursing student, list three things you know about } \\
\text { the profession of physical therapy. }\end{array}$ & $\begin{array}{l}\text { List } 3 \text { benefits of the interprofessional learning experience } \\
\text { you had today. }\end{array}$ \\
\hline $\begin{array}{l}\text { If you are a physical therapy student, list three things you } \\
\text { know about the profession of nursing. }\end{array}$ & $\begin{array}{l}\text { Would you like to have more interprofessional learning } \\
\text { experiences in the future? Why or why not, please explain: }\end{array}$ \\
\hline
\end{tabular}

Qualitative thematic analysis was conducted based on methods as described by Creswell, and Miles, Huberman, and Saldaña. ${ }^{19,20}$ Methods included reading, memoing, and matrix building based on themes generated from the open ended questionnaire. To ensure rigor, multiple members of the team with prior qualitative experience reviewed the questionnaire data. Short answer data was transcribed from the written student narrative into a matrix, and reviewed in its entirety for accuracy and analysis by members of the research team. Several layers of matrices were composed by breaking down the data into parts revealing subsequently emerging patterns and themes. The technique, described by Ayres, Kavanaugh, \& Knafl, enabled each participants' responses to be reviewed within and across cases. ${ }^{21}$ Changes were noted from pre-experience to post-experience and across cases to look at responses from different students from the same discipline. Reviewing within and across cases has been demonstrated as an important qualitative technique to allow for the combination of recognition of individual experiences while capturing variation across experiences. $^{21}$

\section{Orientation and Brief}

All students received an orientation to simulation and the simulated environment by the simulation operations staff one week before the activity. Pre-briefing occurred just prior to IPE, the day of the activity, and was facilitated by BSN and DPT faculty who were part of the study team. The pre-brief included a review of objectives and content related preparation questions specific to the simulation scenario. Students were arranged by BSN and DPT faculty into groups that included one BSN and four to six DPT students. Once the groups were arranged, students were given an opportunity to become familiar with the members of their team and discuss their perceptions of each other's roles. BSN and DPT faculty provided student groups with an electronic educational medical record accessed by the BSN students' for review and planning after they explored each other's roles.

\section{Computerized mannequin simulation}

The focus of the computerized mannequin simulation experience was management and education of a hospitalized patient with a history of a femoral-popliteal bypass graph, COPD, and diabetes. The activity included four BSN and DPT student teams, with 
each team having one of four possible hospital in-patient scenarios aligned with students' academic level. Each of the four scenarios included a single critical incident that required students to work collaboratively.

Student groups rotated in 20-minute blocks, with each group completing one of the four scenarios. Students not actively participating in the simulation observed the activity via live stream on a monitor in a classroom. While observing, students were given instructions to provide comments on a paper divided into plus and delta columns. When all student groups had rotated through the simulated clinical experience, the students were debriefed by PT and BSN faculty using the Plus/Delta method. This approach to debrief is considered learner driven and able to transform perspectives by having student teams identify tasks that went well (plus) and areas where performance could be improved (delta). ${ }^{22}$

\section{Hybrid Simulation}

The focus of the simulated patient experience for the hybrid simulation was a patient in an acute care hospital with type 1 diabetes that required a physical therapy consult associated with a foot wound. The activity consisted of one DPT student in each group assigned the role of the patient. That DPT student received written role-play information to use as a guide. A simulated foot with a wound was provided to each DPT student doing the patient role-play. The script for role-play was developed by the DPT faculty. The BSN and remaining DPT students in each group collaborated to assess the patient and the wound along with providing education and discharge planning to the "patient." For scenario fidelity, all students were directed during the pre-brief on their focus. Promoting realism in role-play promotes engagement in the experience. ${ }^{23}$ The emphasis for BSN students was on diabetes management, while the DPT student's attention was on wound assessment, offloading, and gait training.

Following the simulation activity, students were debriefed as one group in the classroom by BSN and DPT faculty. A three-phase model of debriefing was utilized with faculty facilitators providing an introduction to the debriefing followed by group discussion, probing students' perceptions of the activity. Probing questions included initial reactions, what went well, what challenges were encountered and what could have been done differently. ${ }^{22}$ After the debriefing, one DPT faculty provided additional education to the students regarding wound care management and appropriate offloading devices.

\section{RESULTS}

A total of 186 (186/186) students who participated in the simulated patient scenarios completed the RIPLS questionnaire. Of these, $182(182 / 186 ; 97 \%$ response rate) students completed and returned both the pre and post short-answer qualitative questions. The quantitative data from all students groups was collectively analyzed, as the research questions of the study were to understand BSN and DPT student's perceptions of other healthcare disciplines prior to and after participating in an interprofessional simulation activity. The qualitative data was analyzed for the respective professions both together and separately, as the research team wanted to view the perceptions of each discipline on an individual as well as collective basis.

Fifty-two (28.4\%) of the participants were nursing students and 131 (71.6\%) were DPT students; three students did not indicate their discipline. Students were predominantly female $(n=116,62.7 \%)$ and ranged in age from 20 years to 59 years $(M=24.49$, $S D=4.40)$.

Descriptive values were obtained for each of the four RIPLS subscales. Using frequency histograms and the Kolmogorov-Smirnov $(K S)$ statistic, the data were explored to determine if it met the assumptions necessary for parametric testing. These results are presented in Table 3.

Table 3. Descriptive values and KS statistics for each subscale at pre- and post-simulation experience

\begin{tabular}{|c|c|c|c|c|c|c|c|c|c|c|c|c|}
\hline \multirow[b]{2}{*}{ Measure } & \multicolumn{6}{|c|}{ Pre-simulation } & \multicolumn{6}{|c|}{ Post-simulation } \\
\hline & $n$ & $M$ & $M d n$ & $S D$ & range & $K S(d f)$ & $n$ & $M$ & $M d n$ & $S D$ & range & $K S(d f)$ \\
\hline $\begin{array}{l}\text { Teamwork } \\
\text { and collaboration }\end{array}$ & 180 & 42.0 & 44.0 & 3.77 & {$[28,45]$} & $\begin{array}{l}.23^{* *} \\
(180) \\
\end{array}$ & 175 & 43.3 & 45.0 & 3.35 & {$[29,45]$} & $\begin{array}{l}.40^{* *} \\
(175)\end{array}$ \\
\hline $\begin{array}{l}\text { Negative } \\
\text { professional identity }\end{array}$ & 182 & 12.2 & 13.0 & 3.08 & {$[3,15]$} & $\begin{array}{l}.29^{* *} \\
(182)\end{array}$ & 177 & 13.2 & 15.0 & 2.52 & {$[6,15]$} & $\begin{array}{l}.35^{* *} \\
(177)\end{array}$ \\
\hline $\begin{array}{l}\text { Positive } \\
\text { professional identity }\end{array}$ & 183 & 17.9 & 19.0 & 2.26 & {$[10,20]$} & $\begin{array}{l}.21^{* *} \\
(183)\end{array}$ & 178 & 19.0 & 20.0 & 1.85 & {$[12,20]$} & $\begin{array}{l}.41^{* *} \\
(178)\end{array}$ \\
\hline $\begin{array}{l}\text { Roles and } \\
\text { responsibilities }\end{array}$ & 180 & 6.6 & 6.0 & 2.20 & {$[3,15]$} & $\begin{array}{l}.14^{* *} \\
(180)\end{array}$ & 176 & 6.5 & 6.0 & 2.50 & {$[3,15]$} & $\begin{array}{l}.13^{* *} \\
(176)\end{array}$ \\
\hline
\end{tabular}

${ }^{* \star} p<.001$. Note: Possible range of scores: teamwork and collaboration, 5 to 45 ; negative professional identity, 3 to 15 ; positive professional identity, 4 to 20; roles and responsibilities, 3 to 15 . 
Based on these values, it was determined that the scores were not normally distributed; therefore, non-parametric testing was used to analyze the data. The data was tested to assure that the instrument achieved an acceptable reliability coefficient, alpha (), of at least 0.70 . The scores for each subscale obtained at each administration were evaluated by Cronbach's testing for reliability as internal consistency. The results are presented in Table 4.

Table 4.Instrument reliability as internal consistency

\begin{tabular}{lccccc}
\multicolumn{1}{c}{ Measure } & $\begin{array}{c}\text { Number of } \\
\text { scale items }\end{array}$ & $n$ & Pre-simulation & $n$ & \multicolumn{2}{c}{ Post-simulation } \\
\hline Teamwork and collaboration & 9 & 180 & .89 & 175 & .93 \\
Negative professional identity & 3 & 182 & .87 & 177 & .71 \\
Positive professional identity & 4 & 183 & .82 & 178 & .89 \\
Roles and responsibilities & 3 & 180 & .55 & 176 & .57 \\
Entire scale & 19 & 171 & .83 & 168 & .81 \\
\hline
\end{tabular}

As the values for the subscale measuring roles and responsibilities consistently fell short of achieving the benchmark of 0.70 , it was deemed to have poor reliability among this sample and not used in further analyses. Using the Wilcoxon Signed Ranks test, the non-parametric equivalent to the paired $t$ test, the research questions were answered; post-simulation experience scores were significantly higher than the pre-simulation experience scores; the effect was small to moderate. The results are presented in Table 5 .

Table 5.Results of comparisons of pre-simulation and post-simulation Scores

\begin{tabular}{lccccc}
\hline \multicolumn{1}{c}{ Measure } & Pre-simulation & Post-simulation & & & \\
& Mdn & Mdn & $z$ & $p$ & $r$ \\
\hline Teamwork and collaboration & 44.0 & 45.0 & -5.96 & .00 & -.32 \\
$\begin{array}{l}\text { Negative professional } \\
\text { identity }\end{array}$ & 13.0 & 15.0 & -3.88 & .00 & -.20 \\
Positive professional identity & 19.0 & & & & \\
& & 20.0 & -6.66 & .00 & -.35
\end{tabular}

Next are the qualitative responses which are presented verbatim in language used by the participants. Pseudonyms were created for each response. Analysis of the specific qualitative responses from both BSN and DPT student's shows similarities in perceptions of the other discipline as well as knowledge gaps.

\section{Theme 1: Narrow and Expanded Focus}

Generally, before the IE, both groups of students tended to view the other discipline with a narrow focus. BSN student pre-IPE perceptions of the role of the DPT students included the following:

"They work with post-operative patients, especially orthopedic, to get them discharged, to teach other health care professionals, about how to get the patient to recover, assist individuals when something is physically wrong with the body." - Sydney BSN student

"Assist with ambulation, ADL's in many different ways. Practice active \& passive ROM. Promote speedy recovery" - Sophia BSN Student 
"They work on body mechanics/proper way how to use them. PTs help people (usually injured in some way) regain their strength. PTs focus on physical areas (usually lower extremities)." - Nicole BSN student

The DPT students described the role of the BSN student pre-IPE as:

"They are usually the first health professional to see the patient in a physician office. They get information from the patient before the physician sees them. They assist physicians in the administration of health care." - David DPT student

"They dispense medications, take daily care of the patient and their daily needs and monitor changes in the patient" - Sarah DPT student

"...tasks can be very different depending on the setting, they often see things physicians may miss, and nursing is very hands-on" - Michelle DPT student

Prior to the IPE, BSN students tended to focus on the physical aspects of the role of the DPT, such as patient rehabilitation, range of motion, and ambulation. The DPT students focused on the specific tasks they thought the role of nursing included, such as taking vital signs, administering medications, and assisting physicians. Interestingly, several DPT students showed a wider view of the nursing role, commenting on the challenges of the nursing profession, the long hours, and the compassion required.

Post IPE perceptions of DPT and BSN responses showed an expanded understanding of the other discipline's knowledge, empathy towards the other's professions, and a wider appreciation of the rewards, limitations, and difficulties of each discipline. Comments from both disciplines included:

"They provide wound care, work in a variety of facilities, also have to come up with risks the patient may have and inform nurses" - Jennifer BSN student

"PTs can perform skin assessments. PTs can do vital signs. PTs can debride wounds if necessary/within their scope of practice" - Alyssa BSN student

"They perform assessments. Great breathing techniques. Learned about ambulation and how to treat a patient from physical therapy." - Peter BSN student

"They have a big role in educating patients, they have to report back to doctors; and are the eyes and ears of a doctor, nurses have lots of assessments from head to toe." - Michael DPT student

"I honestly did not know just how much Nursing Students were required to learn. I realized how often we may actually be working together. I realized I need to be around other professionals to truly grasp patient care." - Kerri DPT student

"How thorough the nursing's assessments for the patient are. How similar we are w/ patient education. We are able to share new things we were unaware of about each other's professions." - Rachel DPT student

In the post questionnaire, BSN students remarked on the many aspects of the DPT profession they were previously unaware of, including wound care, and assessing cardiac and respiratory status. However, many BSN respondents still tended to focus on the physical aspects of the care provided by the DPT. DPT students after the IPE, indicated they were impressed with the vast knowledge base and skill level of nursing, including communication, assessment, and their role in planning and implementing healthcare interventions.

\section{Theme 2: Positive Perceptions of Collaboration and IPE}

BSN and DPT students had similar comments regarding the overlap of their scopes of practice and the importance of collaboration and benefits of IPE. Students recognized the importance of working together to provide optimal, efficient, and the best patient care. What both groups reported, in general, was that each discipline brings their own expertise to optimizing patient care. To do so, they must effectively communicate with each other to reinforce what each profession imparts to the patient. Students appeared to recognize the overriding need to support and encourage adherence to each profession's plan of care. Student comments regarding the IPE included: 
"There are things PTs can do to benefit nurses (and vice versa) for pt. teaching/care, PTs can actually make it more efficient for pts to learn body mechanics/care for wounds, etc." - Crystal BSN student

"Being able to work together with PT really helps both disciplines to gain a better understanding of the patient conditions." - Sam BSN student

"It is important for nurses and physical therapist to collaborate during patient care because it would be beneficial for the patient." - Sandi BSN student

"It is important because communication is key in order to treat our patients effectively." - Cheryl DPT student

"B/C it allows for a learning experience for both professions and allows for communication to be beneficial for treatment plan." - Matt DPT student

"It is important for health care professionals to collaborate to provide the best patient care. They each bring their own knowledge and professional duties." - Jason DPT student

For the benefits of IPE, many students remarked on how working with other disciplines improved knowledge of their own profession as well as enhancing knowledge of the other profession. They appreciated the ability to network with other professions and more specifically in a real-life situation outside of the classroom

\section{DISCUSSION}

The results indicated a change in perceptions regarding each disciplines' profession after participation in an immersive IPE activity. Strengths of the study include using a theoretical basis to analyze the data and the previously validated RIPLS questionnaire. Teamwork and collaboration, negative professional identity, and positive professional identity subscales obtained at pre-simulation experience and again at post-simulation experience were significantly different, although the roles and responsibilities subscale was not deemed to be a reliable measurement. Changes between the pre and post questionnaires noted in the RIPLS and the short answer qualitative questions between the pre and post questionnaires seem to suggest that participants gained a better understanding of each other's profession. Based on the interpretation of the results, students seemed to exhibit a transformation of perspective regarding each other's profession.

\section{Limitations}

There are several limitations which effect the generalizability of the study. This includes, but is not limited, to the results only being of DPT and BSN students which may restrict the applicability of the results to other health care professions. Other limitations of the study included unequal numbers between DPT and BSN, with DPT students out numbering the BSN students, which could have impacted the results. Student feedback from the short answer qualitative questions expressed a desire to know more about their own profession before embarking on an IPE experience focused on roles of another discipline. These perceptions may be related to level of learner and their inexperience with collaboration and their own professional role as well as a lack of faculty experience in IPE competencies. A compelling remark from a DPT student (Mark) noted, "I would rather know more about my own profession before attempting to know other professions in order to properly perform best." However, the literature notes that an objective of an IPE activity is to better understand one's own profession, and how interactions with the health team affect those who receive their services. ${ }^{9}$

Another limitation is that students expressed disorganization regarding the experience. This may be related to faculty being novices in IPE simulation. Adequate resource and training of faculty is important for successful infusion of IPE into the curriculum. ${ }^{9,23}$ Since the implementation of this IPE activity, the institution has created and IPE center for the development of faculty and staff.

\section{CONCLUSION}

The majority of the BSN and DPT students viewed the IPE activities positively. Many expressed they would welcome further IPE opportunities. The data supports the finding that BSN and DPT students identified that IPE can improve the perception of each other's profession and scope of practice.

This study reinforces the importance of IPE early in the curriculum. It also highlights that early introduction of IPE supports meaningful learning and assists healthcare students clarify their own roles as they relate to other healthcare providers. ${ }^{2}$ IPE exposes students to identifying their specific discipline's scope of practice, and expands their understanding of how their practice may complement the role of other professions. BSN and DPT students each bring their own strengths to patient care and at times, 
though roles may overlap, it is important for each to support and reinforce the care and patient education they individually and collectively impart to the patient. For future IPE activities, faculty development needs to be addressed to ensure successful implementation and alignment to best practices in IPE design, facilitation, debriefing and evaluation.

Though there exists evidence that interprofessional education is successful, this study adds to the existing body of knowledge in the field of IPE in that the activity was introduced early in the respective disciplines healthcare education programming..$^{11,24}$ Early and consistent simulation exposure to IPE embedded in healthcare curriculum fosters collaboration., $25,26,27$ Future IPE studies are still needed that measure learners perceptions at various levels in their academic career to determine if early encounters are more meaningful for healthcare learners.

\section{REFERENCES}

1. Institute of Medicine. Health Professions Education: A Bridge to Quality. Institute of Medicine (US) Committee on the Health Professions Education Summit 2003; https://www.ncbi.nlm.nih.gov/books/NBK221528/ Accessed January 4, 2018, 2017.

2. Mezirow J. Learning as transformation : critical perspectives on a theory in progress. San Francisco: Jossey-Bass; 2000.

3. World Health Organizaton. Framework for Action on Interprofessional Education \& Collaborative Practice. Geneva, Switzerland: World Health Organization;2010.

4. American Association of Colleges of Nursing. The essentials of baccalaureate education for professional nursing practice. Washington DC2008.

5. Commission on Accrediatation in Physical Therapy Education. Standards and required elements for accreditation of physical therapist education programs. Alexandria, VA 20182018.

6. Interprofessional Collaborative. Core competencies for interprofessional collaborative practice: 2016 update. Washington, DC2016.

7. Cranford JS, Bates T. Infusing Interprofessional Education Into the Nursing Curriculum. Nurse Educator. 2015;40(1):16-20.

8. Williams B, McCook F, Brown T, et al. Are Undergraduate Health Care Students 'Ready' for Interprofessional Learning? A Cross-Sectional Attitudinal Study. Internet Journal of Allied Health Sciences \& Practice. 2012;10(3):119-119.

9. Bridges, D., Davidson, R. A., Soule Odegard, P., Maki, I. V., \& Tomkowiak, J. (2011). Interprofessional collaboration: three best practice models of interprofessional education. Medical education online, 16(1), 6035.

10. Grice GR, McCorkle, N.A. Difference in Student Pharamcist Attitudes and Readiness for Interprofessional Learning after an Activity with Student Nurses. Journal of Interprofessional Education and Practice. 2016;3:29-33.

11. Rose MA, Smith K, Veloski JJ, Lyons KJ, Umland E, Arenson CA. Attitudes of students in medicine, nursing, occupational therapy, and physical therapy toward interprofessional education. Journal of Allied Health. 2009;38(4):196-200.

12. Rossler KL, Kimble LP. Capturing readiness to learn and collaboration as explored with an interprofessional simulation scenario: A mixed-methods research study. Nurse Education Today. 2016;36:348-353.

13. Society for Simulation in Healthcare and National League for Nursing. Interprofessional Education and Healthcare Simulation Symposium. 2012.

14. Kleinheksel, AJ. Tranformative learning through virtual patient simulations: Predicting critical student refelctions. Clinical Simulation in Nursing. 2014;10(6):e301-e308.

15. Zwarenstein M, Reeves S. Knowledge translation and interprofessional collaboration: where the rubber of evidence-based care hits the road of teamwork. Journal of Continuing Education in the Health Professions. 2006;26(1):46-54.

16. McFadyen A, Webster V, Strachan K, Figgins E, Brown H, McKechnie J. The Readiness for Interprofessional Learning Scale: a possible more stable sub-scale model for the original version of RIPLS. Journal of Interprofessional Care. 2005;19(6):595-603.

17. McFadyen AK, Webster VS, Maclaren WM. The test-retest reliability of a revised version of the Readiness for Interprofessional Learning Scale (RIPLS). Journal of Interprofessional Care. 2006;20(6):633-639.

18. Parsell G, Bligh J. The development of a questionnaire to assess the readiness of health care students for interprofessional learning (RIPLS). Medical Education. 1999;33(2):95-100.

19. Creswell JW. Qualitative inquiry \& research design choosing among five approaches. Thousand Oaks, CA: Sage, 2013.

20. Miles MB, Huberman AM, Saldana J. Qualitative data analysis : a methods sourcebook. London, England: Sage; 2014.

21. Ayres L, Kavanaugh K, Knafl KA. Within-case and across-case approaches to qualitative data analysis. Qualitative Health Research. 2003;13(6):871-883.

22. Oriot D, Alinier, Guillaume. Pocket Book for Simulation Debriefing in Healthcare. Cham, Switzerland: Springer International Publishing; 2018.

23. van Soeren, M., Devlin-Cop, S., MacMillan, K., Baker, L., Egan-Lee, E., \& Reeves, S. (2011). Simulated interprofessional education: an analysis of teaching and learning processes. Journal of Interprofessional Care, 25(6), 434-440. 
24. Palaganas, JC, Maxworthy, JC., Epps, CA, Mancini, ME. Defining excellence in simulation programs. Philadelphia, PA: Wolters Kluwer, 2015.

25. Cooper, H., Spencer-Daw, E., Mclean, E. (2005). Beinning the process of teamwork: Design, implementation and evaluation of an inter-professional education intervention for first year undergraduate students. Journal of Interprofessional Care, 19(5), 492-508.

26. Curran, V.R., Sharpe, D., Flynn, K ands Button, P. (2010). A longitudinal study of the effect of an interprofessioal education curriculum on student satisfaction and attitudes towards interprofessional teamwork and education. Journal of Interprofessional Care, 24(1), 41-52.

27. Hind, M., Norman, I., Cooper, S., Gill, E., Hilton, R., Judd, P., Jones, S.C. (2003). Interprofessional perceptions of health care students. Journal of Interprofessional Care, 17(1), 21-34. 